\title{
Elasto-plastic analysis of reinforced concrete slit shear walls
}

\author{
A. K. H. Kwan, BSc (Eng), PhD, CEng, MICE, H. Dai, BEng, MEng, PhD, and \\ Y. K. Cheung, BSc, PhD, DSc, DE, FEng, CEng, FICE, FIStructE
}

This paper deals with the elasto-plastic behaviour of reinforced concrete slit shear walls, a new type of earthquake-resistant wall structure. The softened truss model was used to analyse the inelastic behaviour of the connecting beams, which are the key vibration-control devices of the structure. Based on the non-linear load-deflection curves of the connecting beams obtained using the softened truss model, the elastoplastic behaviour of the slit shear wall structure as a whole was evaluated using a non-linear finite-element method. A parametric study was then carried out to investigate the effects of different connectingbeam designs on the performance of slit shear walls. The results reveal that the depth and reinforcement of the connecting beams directly affect the failure mode and ductility of the slit shear wall structure. It is concluded that, with appropriate design, the conversion of a solid shear wall into a slit shear wall can substantially increase the ductility of the wall structure, but there will be a slight reduction in lateral strength.

Keywords: buildings, structure \& design; concrete structures; seismic engineering

\section{Introduction}

\section{The slit shear wall concept}

An earthquake-resistant building is required to withstand earthquakes without collapsing and without incurring major damage. It is also desirable that the inter-storey distortions are not excessive, as this would cause extensive damage to the non-structures. To accomplish these goals, the structure needs to have: (1) high lateral strength; (2) high ductility; (3) high energy-dissipation capacity; (4) sufficient shear stiffness to limit inter-storey distortions; and (5) a strategic plastification sequence such that members that are not so important for stability and are less difficult to repair will yield first, while members that are critical for stability and are difficult to repair will yield last.

2. It has been suggested that, in addition to strengthening the structure and improving the ductility, etc., the structural system should be de-tuned such that its resonant frequency falls outside the spectrum of the seismic excitation. ${ }^{1}$ In most cases, where the dominant frequency of the seismic excitation is higher than the fundamental frequency of the building structure, the structure can be made more flexible so as to shift its fundamental frequency away from the seismic spectrum and reduce its response. However, there is a limit to the extent to which this can be achieved, because the building needs to have sufficient stiffness to avoid excessive inter-storey distortion when subjected to earthquake attack and excessive vibration when subjected to strong wind.

3. Besides de-tuning, the seismic response may also be reduced by increasing the damping capacity of the structure. A number of specially designed damping systems have been developed. $^{2}$ These may be classified into 'active' and 'passive' systems. Active systems are the most effective, but are costly to install and maintain. Hence, they are limited to important buildings such as hospitals. In relative terms, passive systems are more practicable for ordinary buildings. Passive damping devices may be implemented by adding purpose-made dampers, or by converting some of the structural elements into 'structural dampers' which would first yield during an earthquake and then dissipate vibration energy through their hysteretic stress-strain properties.

4. Many structural forms have been developed for earthquake-resistant buildings. Of these forms, those incorporating some kind of shear wall (e.g. the shear/core wall system and the coupled shear wall-frame system) are generally regarded as being the most efficient. Shear walls serve a triple function: they support gravity loads, they resist wind and earthquake loads, and they act as partitions or enclosures. ${ }^{3}$ Shear wall systems are very effective in reducing inter-storey distortions and can be designed to have fairly high lateral strength. However, due to their high stiffness, they also tend to attract large amounts of seismic energy and, as their energy dissipation capacity is relatively low (there are no plastic hinges that can be formed inside the walls to dissipate energy), the seismic energy absorbed may build up quickly, eventually causing excessively large seismic responses. Most important of all, damage to shear walls is usually centred on the bases. This damaged is difficult to repair because the walls carry gravity loads.

5. In order to overcome these shortcomings, the idea of introducing vertical slits, in order to convert the shear walls into 'slit shear walls',
Proc. Instn Civ. Engrs Structs \& Bldgs, 1998, 128, Nov., 342-350

Paper 11534

Written discussion closes 26 February 1999

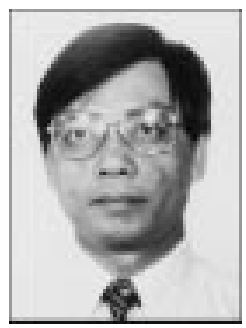

A. K. H. Kwan Senior Lecturer, Department of Civil Engineering, University of Hong Kong

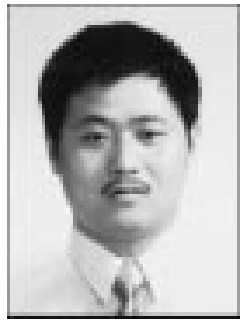

H. Dai, Professor, Department of Architecture, Southeast University, Nanjing

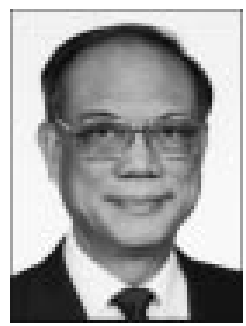

$Y$. K. Cheung, Professor, Department of Civil Engineering, University of Hong Kong 
has recently been proposed. ${ }^{4}$ A slit shear wall is a shear wall with purposely built-in vertical slits, which divide the shear wall into subunits interconnected by shear connections (Fig. 1). To some extent, a slit shear wall is a coupled shear wall structure with very short connecting beams. Under normal wind-load conditions, the connecting beams remain elastic and, due to their shortness and high stiffness, the slit shear wall behaves like a solid wall. When overloaded during an earthquake, however, the connecting beams would yield, leading to significant reduction in stiffness, which would help to de-tune the structural system and reduce the seismic energy input from the earthquake excitation. After yielding, the connecting beams would be transformed into structural dampers, providing passive damping to dissipate the vibration energy. Although the connecting beams would be damaged after the earthquake, their sacrifice would help to protect the wall itself from being damaged and the structure from total collapse. Slit shear walls have the high stiffness required for wind resistance, the low stiffness and high damping desirable for earthquake resistance, small inter-storey distortions during vibrations, and a well-planned plastification sequence. Such walls could thus be advantageous in tall buildings, which require both wind and earthquake resistance.

\section{Previous studies}

6. The connecting beams in slit shear walls are much shorter than those in ordinary coupled shear wall structures, and may thus behave differently. Cheung et al. ${ }^{5,6}$ have conducted monotonic and cyclic shear tests on isolated connecting beams in slit shear walls. They found that conventional beam theories are not applicable to such connecting beams. One important phenomenon observed is that the short connecting beams would fail only in shear, with diagonal compression struts formed inside and all longitudinal reinforcement bars in tension.

7. Large-scale model tests of reinforced concrete slit shear walls have also been conducted. ${ }^{7}$ The results revealed that the stiffness and strength of the connecting beams have great influence on the elasto-plastic behaviour of slit shear wall structures. Two failure modes have been identified. In slit shear walls with weak connecting beams, the connecting beams would yield before the walls fail. On the other hand, when the connecting beams are strong, the slit shear walls would fail (like solid walls) without yielding of the connecting beams.

8. With regard to theoretical studies, the elastic behaviour of slit shear walls has been analysed using the continuous-connection method and the finite-element method. ${ }^{4}$ To date, there has been no detailed elasto-plastic analysis of slit shear walls.

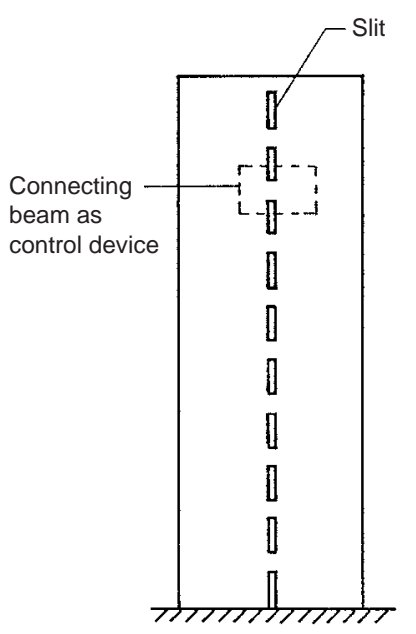

(a)

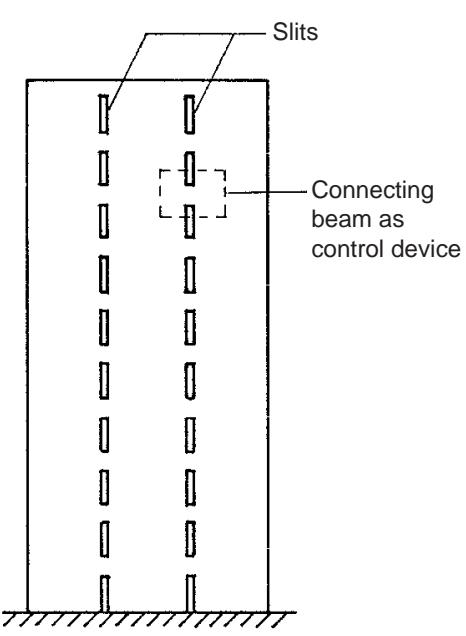

(b)

\section{Present study}

9. The present study consisted of two parts. The first part comprised theoretical modelling of the short connecting beams. It was hoped that the theoretical model would help to explain the experimentally observed behaviour and provide a non-linear load-deflection relationship of the structural component. In the second part, the theoretical model for the connecting beams was implemented in a non-linear finiteelement program to evaluate the elasto-plastic behaviour of the slit shear wall system. A parametric study was then carried out to investigate the influence of various structural parameters on the performance of slit shear walls.

\section{Analysis of the connecting beams by softened truss model theory}

10. Although experimental studies on connecting beams have been carried out, ${ }^{5,6}$ no theoretical method for analysing their inelastic behaviour has been available. It is recognized that, because of their small span/depth ratios, the behaviour of connecting beams is governed mainly by shear, which is much more difficult to treat than flexure.

11. There are many different methods for analysing shear in reinforced concrete, but most of them are highly empirical. In recent years, however, the softened truss model theory ${ }^{8,9}$ has emerged as the most promising approach. It holds that a concrete element reinforced with orthogonal steel bars and subjected to shear stresses will develop diagonal cracks. These cracks will separate the concrete into a series of diagonal concrete struts, which are assumed to resist axial compression. Together with the steel bars, which are assumed to take only axial tension, the struts form a truss action to resist the applied shear stresses. The failure mechanism of the connecting beams, as observed during testing, is very similar to the truss mechanism described by the softened truss model theory. Hence, the theory may also be
Fig. 1. The proposed slit shear wall system with: (a) one band of slits; (b) two bands of slits 
used to analyse the inelastic behaviour of the connecting beams.

12. A typical connecting beam and its truss analogy after the concrete has cracked are shown in Fig. 2. Two coordinate systems are employed for the analysis. For the connecting beam as a whole, an $x, y$ coordinate system with its axes parallel to the longitudinal and transverse directions is used. For the diagonal concrete struts, a separate $d, r$ coordinate system, with the $d$ axis parallel to the struts, is used. Stresses in the $x, y$ coordinate system are denoted by $\sigma_{x}, \sigma_{y}$ and $\tau_{x y}$, while those in the $d, r$ coordinate system are denoted by $\sigma_{d}, \sigma_{r}$ and $\tau_{d r}$, respectively. Strains are similarly denoted.

Tension is taken as positive.

13. Assuming the steel to be elasticperfectly plastic, the stress-strain relationships of the longitudinal and transverse steel reinforcement can be expressed in the following form:

$$
\begin{aligned}
& f_{x}= \begin{cases}E_{\mathrm{s}} \varepsilon_{x} & \left(\left|\varepsilon_{x}\right| \leq \varepsilon_{\mathrm{sy}}\right) \\
f_{\mathrm{sy}} & \left(\left|\varepsilon_{x}\right| \geq \varepsilon_{\mathrm{sy}}\right)\end{cases} \\
& f_{y}= \begin{cases}E_{\mathrm{s}} \varepsilon_{y} & \left(\left|\varepsilon_{y}\right| \leq \varepsilon_{\mathrm{sy}}\right) \\
f_{\mathrm{sy}} & \left(\left|\varepsilon_{y}\right| \geq \varepsilon_{\mathrm{sy}}\right)\end{cases}
\end{aligned}
$$

where $f_{x}$ and $f_{y}$ are the axial stresses in the longitudinal and transverse rebars, and $E_{\mathrm{s}}, f_{\mathrm{sy}}$ and $\varepsilon_{\text {sy }}$ are the Young's modulus, yield stress and yield strain of the steel, respectively.

14. Using the softened concrete model proposed by Vecchio and Collins, ${ }^{8}$ the normal stress of the concrete in the $d$ direction is given by:

$$
\sigma_{d}=-\varsigma f_{c}^{\prime}\left[2\left(\frac{\varepsilon_{d}}{\varsigma \varepsilon_{0}}\right)-\left(\frac{\varepsilon_{d}}{\varsigma \varepsilon_{0}}\right)^{2}\right]
$$

when $\varepsilon_{d} \geq \varsigma \varepsilon_{0}$, and

$$
\sigma_{d}=-\varsigma f_{c}^{\prime}\left\{1-\left[\frac{\left(\varepsilon_{d} / \varsigma \varepsilon_{0}\right)-1}{(2 / s)-1}\right]^{2}\right\}
$$

when $\varepsilon_{d} \leq \varsigma \varepsilon_{0}$. In the above equations $f_{\mathrm{c}}^{\prime}$ and $\varepsilon_{0}$ are the maximum compressive stress and the corresponding axial strain of a concrete cylinder, and $s$ is a softening coefficient. The normal stress in the $r$ direction is actually the tensile stress across the cracks; it is neglected and hence,

$$
\sigma_{r}=0
$$

15. For compatibility, the strain components must satisfy the following equations:

$$
\begin{aligned}
& \varepsilon_{x}=\varepsilon_{d} \cos ^{2} \alpha+\varepsilon_{r} \sin ^{2} \alpha \\
& \varepsilon_{y}=\varepsilon_{d} \sin ^{2} \alpha+\varepsilon_{r} \cos ^{2} \alpha \\
& \gamma_{x y}=2\left(\varepsilon_{d}-\varepsilon_{r}\right) \sin \alpha \cos \alpha
\end{aligned}
$$

On the other hand, the equilibrium conditions that must be satisfied are:

$$
\begin{aligned}
& \sigma_{x}=\sigma_{d} \cos ^{2} \alpha+\sigma_{r} \sin ^{2} \alpha+\rho_{x} f_{x} \\
& \sigma_{y}=\sigma_{d} \sin ^{2} \alpha+\sigma_{r} \cos ^{2} \alpha+\rho_{y} f_{y} \\
& \tau_{x y}=\left(\sigma_{d}-\sigma_{r}\right) \sin \alpha \cos \alpha
\end{aligned}
$$

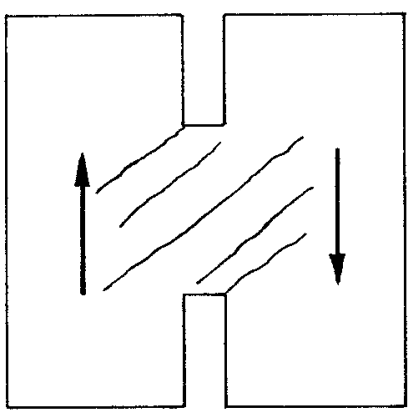

(a)
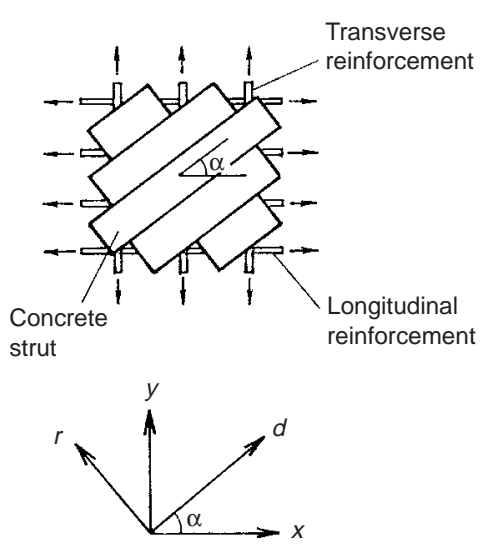

(b)

where $\rho_{x}$ and $\rho_{y}$ are the longitudinal and transverse steel ratios, respectively.

16. Using the above equations, all quantities can be expressed in terms of the three independent variables $\varepsilon_{d}, \varepsilon_{r}$ and $\alpha$. Thus, there are three unknowns to be solved for. Further reduction in the number of unknowns requires consideration of the boundary conditions. The first boundary condition is related to the transverse strain in the beam. As the beam is connected at both ends to large wall panels which will resist any transverse deformation of the beam, the transverse strain may be neglected, i.e.

$$
\varepsilon_{y}=0
$$

The second condition is that there is no longitudinal stress acting on the beam. Hence,

$$
\sigma_{x}=0
$$

Substitution of equation (11) into equation (6) and equation (12) into equation (8) gives:

$$
\begin{gathered}
\varepsilon_{r}=-\varepsilon_{d} \tan ^{2} \alpha \\
\cos ^{2} \alpha=\frac{-\rho_{x} f_{x}}{\sigma_{d}}
\end{gathered}
$$

from which $\varepsilon_{r}$ and $\alpha$ can be determined for any given value of $\varepsilon_{d}$. The inelastic behaviour of the connecting beam can now be studied in detail by treating $\varepsilon_{d}$ as an independent variable. The value of $\varepsilon_{d}$ is increased from zero in small increments until the concrete is completely crushed, and the stress and strain components in the beam corresponding to each value of $\varepsilon_{d}$ determined. From the results so obtained, the relationship between the shear stress $\tau_{x y}$ and the shear strain $\gamma_{x y}$ can be evaluated.

17. In order to verify the applicability of the above theory, the connecting beams tested previously ${ }^{5}$ were analysed. The material properties measured during the tests were: concrete cube strength $35.5 \mathrm{~N} / \mathrm{mm}^{2}$; steel yield strength $342 \mathrm{~N} / \mathrm{mm}^{2}$; and steel Young's modulus $200 \mathrm{kN} / \mathrm{mm}^{2}$. In the analysis, $f_{\mathrm{c}}^{\prime}$ of the concrete and the strain $\varepsilon_{0}$ were taken as 0.8 of the cube strength and -0.002 , respectively. The
Fig. 2. Application of the softened truss model theory: (a) typical crack pattern of a connecting beam; (b) the truss model 
Table 1. Comparison of the softened truss model analysis results with the beam test results

\begin{tabular}{|c|c|c|c|c|c|}
\hline $\begin{array}{l}\text { Beam } \\
\text { specimen } \\
\text { series }\end{array}$ & $\begin{array}{l}\text { Steel ratio, } \\
\rho_{x}\end{array}$ & $\begin{array}{l}\text { Tested shear } \\
\text { strength: } \mathrm{kN}\end{array}$ & $\begin{array}{l}\text { Tested failure } \\
\text { mode }\end{array}$ & $\begin{array}{l}\text { Theoretical shear } \\
\text { strength: } \mathrm{kN}\end{array}$ & $\begin{array}{l}\text { Theoretical failure } \\
\text { mode }\end{array}$ \\
\hline IS-5M & 0.030 & $40 \cdot 0$ & $\begin{array}{l}\text { Concrete fails } \\
\text { without steel } \\
\text { yielding }\end{array}$ & $40 \cdot 2$ & $\begin{array}{l}\text { Concrete fails } \\
\text { without steel } \\
\text { yielding }\end{array}$ \\
\hline IS-10M & 0.015 & $63 \cdot 2$ & $\begin{array}{l}\text { Steel yields before } \\
\text { concrete fails }\end{array}$ & $61 \cdot 7$ & $\begin{array}{l}\text { Steel yields before } \\
\text { concrete fails }\end{array}$ \\
\hline IS-15M & 0.015 & $74 \cdot 8$ & $\begin{array}{l}\text { Steel yields before } \\
\text { concrete fails }\end{array}$ & 89.9 & $\begin{array}{l}\text { Steel yields before } \\
\text { concrete fails }\end{array}$ \\
\hline IS $-20 \mathrm{M}$ & 0.011 & $87 \cdot 6$ & $\begin{array}{l}\text { Steel yields before } \\
\text { concrete fails }\end{array}$ & $91 \cdot 3$ & $\begin{array}{l}\text { Steel yields before } \\
\text { concrete fails }\end{array}$ \\
\hline
\end{tabular}

*The ratio of the area of longitudinal steel reinforcement to the area of the concrete section.

theoretical results are compared with the test results in Table 1 . It can be seen that the theory predicts fairly accurately not only the shear strength but also the failure modes of the beams.

\section{General behaviour of the connecting beams}

18. A parametric study was carried out to evaluate the shear behaviour of connecting beams with different amounts of reinforcement. Details of the beams analysed are given in Table 2. Same dimensions and materials as in previous study are assumed.

19. The shear stress-strain curves of the beams are plotted in Fig. 3. Three possible failure modes are revealed. For a beam with a large amount of reinforcement (beam A), the compressive stress in the concrete struts reaches the maximum value before the steel yields, and immediately afterwards the load-carrying capacity of the beam drops rapidly leading to a brittle mode of failure. For a beam having a relatively small amount of steel (beams C, D and E), the steel yields before the concrete struts reach their maximum stresses, and thereafter the load-carrying capacity of the beam remains almost constant until the concrete struts are crushed, leading to a ductile mode of failure. In between, there is an intermediate case (beam B) characterized by nearly simultaneous yielding of steel and crushing of concrete.

20. The shear strength and ductility factors (defined as the ratio of the deformation at $80 \%$

Table 2. Connecting beams analysed using the softened truss model theory

\begin{tabular}{l|c|c|c}
\hline Beam & $\begin{array}{c}\text { Steel ratio, } \\
\rho_{x}\end{array}$ & $\begin{array}{c}\text { Shear strength: } \\
\mathrm{MPa}\end{array}$ & $\begin{array}{c}\text { Ductility } \\
\text { factor }\end{array}$ \\
\hline $\mathrm{A}$ & 0.030 & 10.5 & 1.48 \\
$\mathrm{~B}$ & 0.020 & 9.8 & 1.54 \\
$\mathrm{C}$ & 0.015 & 8.4 & 2.32 \\
$\mathrm{D}$ & 0.010 & 6.7 & 3.76 \\
$\mathrm{E}$ & 0.006 & 4.9 & 4.65 \\
\hline
\end{tabular}

maximum load in the descending branch of the load-deformation curve to the deformation at maximum load) were evaluated from the stress-strain curves (see Table 2). It can be seen that the ductility decreases rapidly as the steel ratio increases. Thus, for maximum ductility, the steel ratio should be as low as possible. A ductility factor of about 4 or higher can be achieved if the steel ratio is kept below $1 \%$. The higher ductility at smaller steel ratios is, however, achieved at the expense of lower shear strength. This does not really matter much because, if necessary, the reduction in shear strength can be recovered by increasing the depth of the connecting beams.

\section{Elasto-plastic analysis of slit shear walls}

\section{Numerical procedure}

21. For the elasto-plastic analysis, an iterative procedure, with the loads applied incrementally, was used. At each increment step, direct iteration using the secant stiffness of the structure in the analysis was employed. Details of such a direct iteration method have been given by Zienkiewicz and Taylor. ${ }^{10}$ In this method, the loads can be applied either directly, or indirectly in the form of prescribed displacements at the loading points. In the present study, in order to obtain the post-peak behaviour of the structure for ductility evaluation, the loads were applied indirectly through

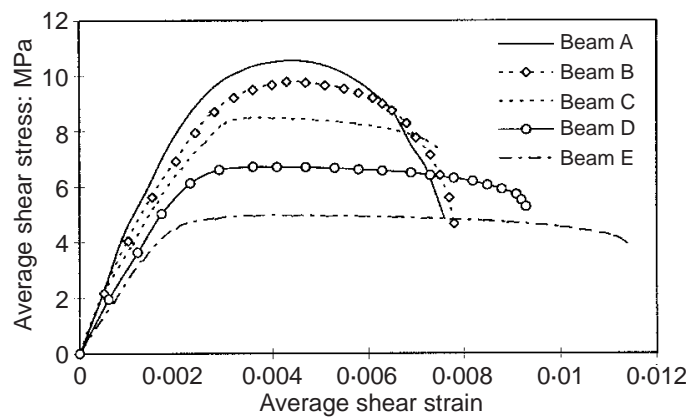

Fig. 3. Shear stress-strain curves of the connecting beams analysed 
prescribed displacements, as is done in loading tests carried out under displacement control.

\section{Stress-strain relationships}

22. The steel reinforcement bars were assumed to be elastic-perfectly plastic, having the same stress-strain relationships as those given in equations (1) and (2).

23. In tension, the concrete was idealized as a linearly elastic brittle material. Before cracking, the secant Young's modulus was taken as the same as the initial Young's modulus. After cracking, the secant Young's modulus in the principal tension direction was taken as zero. In compression, the concrete exhibits extensive non-linearity. Although the wall panels are theoretically under a biaxial stress state, experience with shear wall analysis indicates that the vertical stresses are generally much larger than the horizontal stresses. Hence, the biaxial stress state in shear walls is approximately uniaxial. In the present analysis, therefore, the stress-strain relationship for the concrete can be simplified by assuming that the Young's modulus varies with the larger compressive principal strain, as in the uniaxial case. The stress-strain curve used is the same as the one given by equation (3).

\section{Non-linear load-deflection relationship of the connecting beams}

24. From the shear-strain relationship obtained using the softened truss model, the shear load-deflection relationship for the connecting beams can be evaluated as

$$
\begin{aligned}
& S=\tau_{\mathrm{xy}} t d \\
& \Delta=\gamma_{x y} l
\end{aligned}
$$

where $\tau_{x y}$ and $\gamma_{x y}$ are the shear stress and strain in the connecting beam, $S$ and $\Delta$ are the shear load and deflection of the connecting beam, and $t, d$ and $l$ are the thickness, depth and effective length of the connecting beam, respectively. Observations from model testing of the connecting beams ${ }^{5,6}$ have revealed that the inclined cracks formed inside the beams actually extend well into the walls (see Fig. 2(a)). As a result, there are substantial local deformations near the beam-wall joints that would contribute significantly to the total shear deflections of the beams. One simple way of accounting for the local deformations is to take the effective length of the beam as the total length of the cracked zone, which can be evaluated as

$$
l=a+d \tan \alpha
$$

where $a$ is the clear span of the beam and $\alpha$ is the angle of inclination of the cracks. The plot of $S$ versus $\Delta$ so evaluated is pre-stored by the computer program.

Plane stress element for modelling the wall panels 25 . The wall panels are modelled by a plane stress element which is a four-node isoparametric quadrilateral element with two extra nonconforming bending modes to remove shear locking. A $3 \times 3$ grid of Gaussian points is used in the numerical integration to obtain the element stiffness matrix. The constitutive matrix $[D]$ used consists of two parts. One part $[D]_{c}$ is contributed by the concrete, and the other part $[D]_{\mathrm{S}}$ is contributed by the steel reinforcement inside the concrete:

$$
[\mathbf{D}]=[\mathbf{D}]_{\mathrm{c}}+[\mathbf{D}]_{\mathrm{s}}
$$

The matrix for the concrete $[\mathbf{D}]_{\mathrm{c}}$ is formulated in the usual way, taking into account cracking and non-linearity of the material. On the other hand, the matrix for steel $[\mathbf{D}]_{\mathrm{s}}$ is formulated by spreading the steel reinforcement throughout the volume of the element.

\section{Shear linkage element for modelling the connecting beams}

26. The shear linkage element used to model the connecting beams is a four-node rectangular element the shear load-deflection relationship of which follows that obtained using the softened truss model theory. It is formulated simply as a bilinear plane stress element, with the exception that the shear modulus $\boldsymbol{G}$ is continuously adjusted (see below). With the nodes numbered as shown in Fig. 4, the shear deflection of the element is given by

$$
\begin{aligned}
\Delta= & \frac{1}{2}\left[v_{1}-v_{2}+v_{3}-v_{4}\right] \\
& +\frac{a}{2 d}\left[u_{1}+u_{2}-u_{3}-u_{4}\right]
\end{aligned}
$$

where $u_{i}$ and $v_{i}$ are the horizontal and vertical displacement at node $i$. From the shear deflection $\Delta$ so evaluated, the shear load $S$ acting on the vertical edges of the element can be determined by looking up the pre-stored $S$ versus $\Delta$ curve. Having evaluated the values of $\Delta$ and $S$, the shear modulus $\boldsymbol{G}$ is then adjusted such that the secant shear stiffness of the element, given by $G t d / a$, is equal to $S / \Delta$.

\section{Comparison with experimental results}

27. In order to verify the applicability and accuracy of the proposed method of analysis, the method was applied to the slit shear wall model SM-1, which had been previously tested

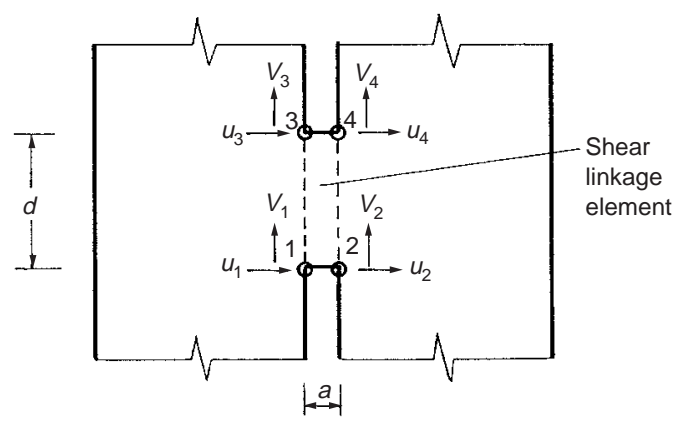

Fig. 4. Shear linkage element used to model the connecting beams 
under monotonic loading by the authors. ${ }^{7}$ The dimensions and loading arrangement of the model are shown in Fig. 5. Major material properties are: concrete cube strength $35.0 \mathrm{~N} / \mathrm{mm}^{2}$; concrete tensile strength $3.5 \mathrm{~N} / \mathrm{mm}^{2}$; steel yield strength $346 \mathrm{~N} / \mathrm{mm}^{2}$; and steel Young's modulus $200 \mathrm{kN} / \mathrm{mm}^{2}$. Some of analytical results and the corresponding model test results are given in Table 3 . The crack pattern and failure mode of the model, as obtained using the proposed method, and the corresponding experimentally observed results are given in Fig. 5. The results show that the analytical results, including the initial stiffness, cracking load, yielding load, ultimate lateral strength, crack pattern and failure mode, of the model are in good agreement with the experimental results.

\section{Parametric study of slit shear walls}

28. A parametric study of the behaviour of slit shear walls with one central band of vertical slits was carried out using the newly developed method of analysis. The slit shear wall model used for the study has the same overall dimensions and material properties as the model SM-1 (see above). In order to investigate the effects of different beam designs on the performance of slit shear walls, the depth of the beams and the amount of longitudinal reinforcement in the beams were taken as the parameters to be studied. A total of eight slit shear wall models was analysed. For comparison, a solid wall model was also included in the study.

29. The loading arrangement is shown in Fig. 6. Unlike the case analysed above, a vertical load of $240 \mathrm{kN}$ was applied to each model in order to simulate gravity load effects. The vertical loads, being permanent, were applied as constant loads to the models before all other loads were applied. After the vertical loads had been applied, lateral loads were then applied in the form of prescribed lateral displacements at the top of the models, like the application of loads under displacement control.

30. From the finite-element results for each model, the lateral load-deflection curve was derived and the deflections at which the beams and the wall started to yield evaluated. The lateral strength and the ductility factor (the ratio of the lateral deflection at $80 \%$ peak load in the descending branch of the load-deflection curve

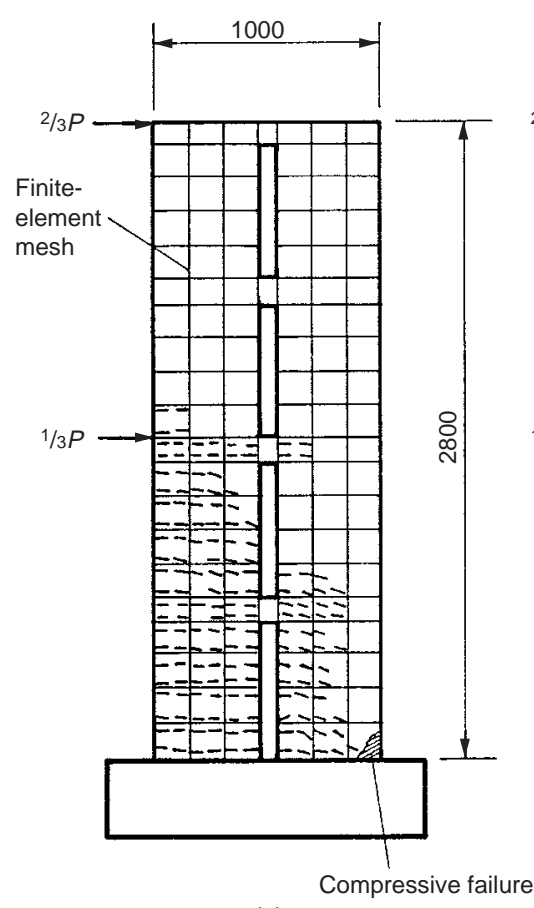

(a)

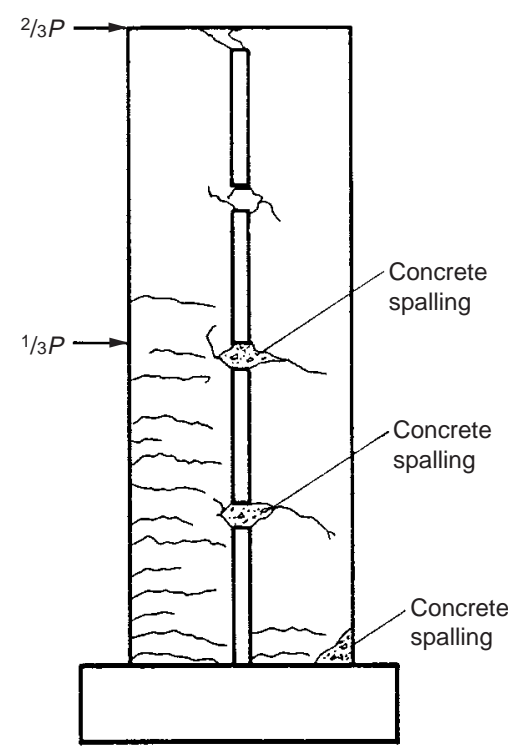

(b)

to the deflection at peak load) of the model were then determined from the load-deflection curve.

\section{Solid shear wall}

31. The main analytical results for the solid shear wall studied are presented in Table 4 , and the load-deflection curve is plotted in Fig. 8. Although the wall failed basically by bending and the failure was preceded by steel yielding, the ductility of the wall was rather limited because of the high vertical compression load acting on it.

\section{Slit shear walls, connecting beam depth $50 \mathrm{~mm}$}

32. Three slit shear wall models with $50 \mathrm{~mm}$ deep connecting beams were analysed. The results obtained (Table 5 and Fig. 7) reveal that all the connecting beams in the three models yielded well before the walls themselves (more specifically, the steel reinforcement bars inside the walls) started to yield. In particular, in the model with the weakest beams, the beams yielded so early that, by the time the wall had reached its ultimate strength, the ductility of the beams had become almost exhausted. Due to the relatively low strength and early yielding of
Fig. 5. Details of model SM-1 (all dimensions in mm): (a) analytical results, $P=52.0 \mathrm{kN}$ at failure; (b) experimental results, $P=49.5 \mathrm{kN}$ at failure

Table 3. Comparison between analytical and experimental results for model SM-1

\begin{tabular}{l|l|c}
\hline & Analytical & Experimental \\
\hline Initial stiffness, $P / \Delta: \mathrm{kN} / \mathrm{mm}$ & $18 \cdot 2$ & $16 \cdot 9$ \\
Load when wall starts to crack: $\mathrm{kN}$ & $21 \cdot 0$ & $24 \cdot 0$ \\
Load when rebars in wall start to yield: $\mathrm{kN}$ & $38 \cdot 5$ & $40 \cdot 6$ \\
Stage when connecting beams yield & Just before overall & Just before overall \\
& failure of model & $49 \cdot 5$ \\
Ultimate lateral strength: $\mathrm{kN}$ & $52 \cdot 0$ & model \\
\hline
\end{tabular}


the connecting beams, the lateral strengths of the shear walls were severely impaired. Compared to the solid shear wall having the same dimensions and reinforcement details, the lateral strengths of the three models were reduced by $40-47 \%$. On the other hand, it is evident that the introduction of slits led to a significant increase in ductility. Of the three models, the two with the stronger connecting beams showed a larger increase in ductility. The model with the weakest connecting beams had a ductility factor only marginally higher than that of the solid wall model.

\section{Slit shear walls, connecting beam depth $100 \mathrm{~mm}$}

33. Three slit shear wall models with $100 \mathrm{~mm}$ deep connecting beams were analysed. The results are presented in Table 6 and Fig. 8 . For the model with a steel ratio of 0.005 in its connecting beams, the beams started to yield long before the wall did. Due to limited ductility of the beams, the shear resistance of the beams gradually decreased after yielding, until the wall reached its ultimate strength, when the beams had little residue strength left. As a result, this model gave a relatively low ultimate strength compared to the other two models. Moreover, as the beams contributed very little to the postpeak resistance of the model, this model also has a relatively low ductility. For the two other models (steel ratio 0.010 and 0.015 in the connecting beams), however, the beams did not start yielding until the walls were about to yield. Thus, despite their limited ductility, the beams were able to maintain their shear resistance until the walls reached the ultimate state. Even when the models entered the post-peak state, the beams could still provide some residue shear resistance to contribute to the post-peak resistance of the structures. Consequently, these two models gave much higher strength and ductility than the first one. Compared to the solid shear wall model without any slits, the lateral strengths given by these two models are 13-23\% lower, but the ductility factors are more than $300 \%$ higher.

Slit shear walls, connecting beam depth $150 \mathrm{~mm}$

34. Two slit shear wall models with $150 \mathrm{~mm}$ deep connecting beams were analysed. The results are given in Table 7 and Fig. 9. The connecting beams in these two models are much stronger than those in the previous models. Because of their high strength, the beams did not yield even when the walls yielded. Roughly speaking, the beams yielded just prior to the walls reaching their ultimate state. As the beams were capable of contributing their full strength towards the ultimate strength of the overall structures, these two models gave much higher strengths than did the previous ones. The lateral strengths are almost the same as that of the solid wall model. At the same time, however, the

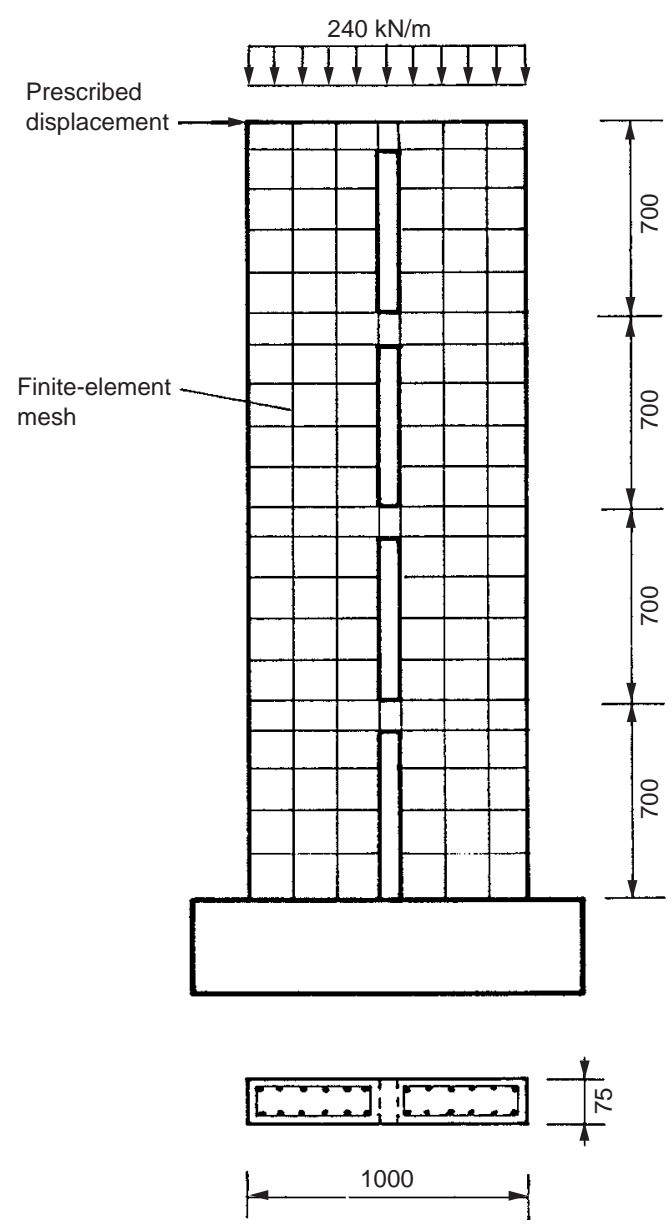

Fig. 6. Slit shear wall model used for the parametric study (all dimensions in $\mathrm{mm}$ )

Table 4. Analytical results for a solid shear wall

\begin{tabular}{l|c}
\hline & Solid shear wall \\
\hline Deflection when wall starts to crack: $\mathrm{mm}$ & $2 \cdot 1$ \\
Deflection when rebars in wall start to yield: $\mathrm{mm}$ & $3 \cdot 8$ \\
Ultimate lateral strength: $\mathrm{kN}$ & $80 \cdot 8$ \\
Ductility factor & 1.58 \\
\hline
\end{tabular}

Table 5. Analytical results for slit shear walls with $50 \mathrm{~mm}$ deep connecting beams

\begin{tabular}{l|c|c|c}
\hline \multirow{2}{*}{} & \multicolumn{3}{|c}{ Steel ratio in connecting beams } \\
\cline { 2 - 4 } & $0 \cdot 005$ & 0.010 & $0 \cdot 015$ \\
\hline Deflection when first beam starts to yield: $\mathrm{mm}$ & $2 \cdot 1$ & $2 \cdot 3$ & $3 \cdot 0$ \\
Deflection when all beams have yielded: $\mathrm{mm}$ & $2 \cdot 3$ & $3 \cdot 1$ & $4 \cdot 0$ \\
Deflection when wall starts to crack: $\mathrm{mm}$ & $3 \cdot 1$ & $3 \cdot 0$ & $2 \cdot 5$ \\
Deflection when rebars in wall start to yield: $\mathrm{mm}$ & $7 \cdot 3$ & 6.9 & $4 \cdot 8$ \\
Ultimate lateral strength: $\mathrm{kN}$ & $42 \cdot 5$ & $45 \cdot 7$ & $48 \cdot 2$ \\
Ductility factor & 1.99 & $2 \cdot 65$ & $2 \cdot 47$ \\
\hline
\end{tabular}


shear deflections of the beams were very small, even when the structures failed. As a result, these two models behaved more like a solid shear wall than a coupled wall structure. Their load-deflection curves are similar to that of the solid shear wall model, and consequently their ductility factors are only marginally higher than that of the solid wall model.

\section{Discussion}

35. From the above analysis, it is evident that the conversion of a solid shear wall into a slit shear wall in which the connecting beams would yield before the wall starts to yield can substantially increase the ductility of the structure. Both the depth and steel ratio of the connecting beams have great influence on the ductility of a slit shear wall structure. If both the depth and steel ratio of the connecting beams are large, the beams will be relatively strong and the wall structure will behave like a solid shear wall. In such a case there will be little increase in ductility compared with that of a solid wall. If the depth and steel ratio of the connecting beams are such that the beams have high ductility and start to yield not too long before the wall does, then the wall structure will behave like a coupled shear wall structure, and there will be a substantial increase in ductility. Lastly, if both the depth and steel ratio of the connecting beams are small, the beams may yield prematurely and, by the time the wall yields, the limited ductility of the beams may be used up. In this case, there will again be little increase in ductility.

36. Summing up, it can be seen that the conversion of a solid shear wall into a slit shear wall is a two-edged sword: it has the detrimental effect of reducing the lateral strength, and at the same time the beneficial effect of increasing the ductility. There is a certain optimum design of the connecting beams for improving the ductility of the wall structure without too much sacrifice in lateral strength. For the beams to yield before the wall does, the beams should not be designed to have a higher yield strength than the shear load that they will be subjected to if they remain elastic when the wall yields. To avoid premature yielding, it is suggested that the connecting beams should be designed to have a yield strength of at least $50 \%$ of the aforementioned shear load. The results obtained so far indicate that, with the connecting beams so designed, the reduction in lateral strength of the wall structure will be of the order of, at most, $30 \%$, but there could be a more than $300 \%$ increase in the ductility of the structure. In the design of wall structures for seismic resistance, it is believed that ductility is more important than strength, and the improvement in ductility at the expense of a slight reduction in strength could, in the end, significantly improve the seismic performance.

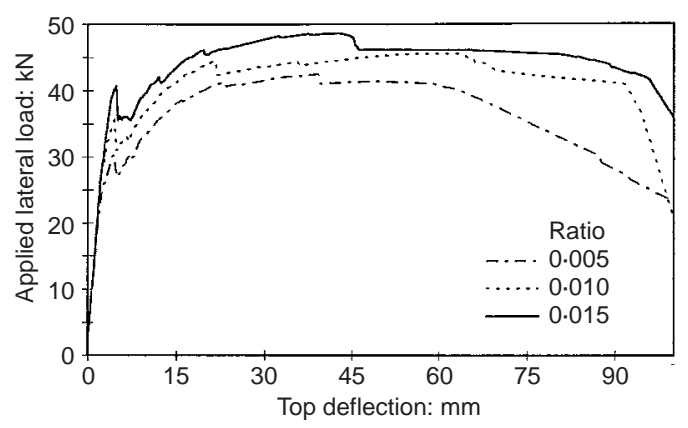

Fig. 7. Load-deflection curves for models with $50 \mathrm{~mm}$ deep connecting beams

Table 6. Analytical results for slit shear walls with $100 \mathrm{~mm}$ deep connecting beams

\begin{tabular}{l|c|c|c}
\hline \multirow{2}{*}{} & \multicolumn{3}{|c}{ Steel ratio in connecting beams } \\
\cline { 2 - 4 } & $0 \cdot 005$ & $0 \cdot 010$ & 0.015 \\
\hline Deflection when first beam starts to yield: $\mathrm{mm}$ & $2 \cdot 3$ & $2 \cdot 6$ & $4 \cdot 2$ \\
Deflection when all beams have yielded: $\mathrm{mm}$ & $3 \cdot 9$ & $6 \cdot 3$ & $7 \cdot 8$ \\
Deflection when wall starts to crack: $\mathrm{mm}$ & $2 \cdot 3$ & $2 \cdot 4$ & $2 \cdot 2$ \\
Deflection when rebars in wall start to yield: $\mathrm{mm}$ & $6 \cdot 5$ & $5 \cdot 4$ & $5 \cdot 2$ \\
Ultimate lateral strength: $\mathrm{kN}$ & $55 \cdot 3$ & $62 \cdot 3$ & $70 \cdot 1$ \\
Ductility factor & $2 \cdot 10$ & $4 \cdot 89$ & $5 \cdot 38$ \\
\hline
\end{tabular}

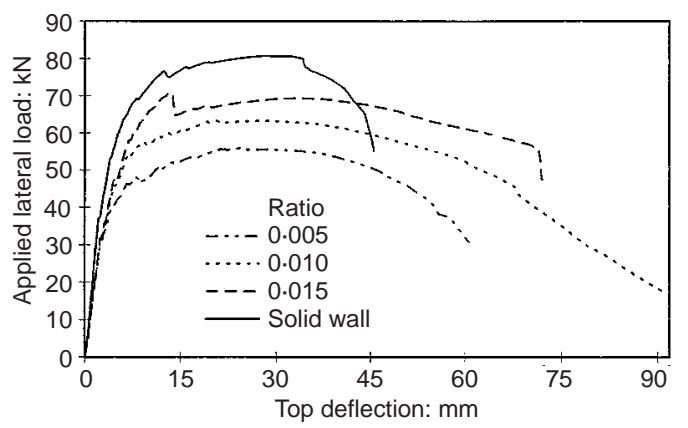

Fig. 8. Load-deflection curves for solid wall model and models with $100 \mathrm{~mm}$ deep connecting beams

Table 7. Analytical results for slit shear walls with $150 \mathrm{~mm}$ deep connecting beams

\begin{tabular}{|c|c|c|}
\hline & \multicolumn{2}{|c|}{$\begin{array}{c}\text { Steel ratio in } \\
\text { connecting beams }\end{array}$} \\
\hline & 0.005 & $0 \cdot 010$ \\
\hline Deflection when first beam starts to yield: $\mathrm{mm}$ & $6 \cdot 5$ & $7 \cdot 9$ \\
\hline Deflection when all beams have yielded: mm & $9 \cdot 7$ & $11 \cdot 8$ \\
\hline Deflection when wall starts to crack: mm & $2 \cdot 2$ & $2 \cdot 1$ \\
\hline Deflection when rebars in wall start to yield: $\mathrm{mm}$ & $3 \cdot 8$ & $3 \cdot 7$ \\
\hline Ultimate lateral strength: $\mathrm{kN}$ & $70 \cdot 1$ & $73 \cdot 8$ \\
\hline Ductility factor & $2 \cdot 32$ & $1 \cdot 84$ \\
\hline
\end{tabular}

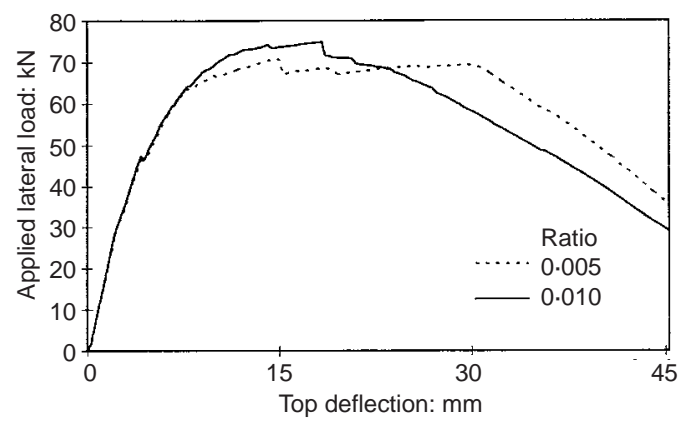

Fig. 9. Load-deflection curves for models with $150 \mathrm{~mm}$ deep connecting beams 


\section{Conclusions}

37. The softened truss model theory has been applied to the analysis of the short connecting beams in slit shear walls. Comparison with experimental results verified the applicability of the model to such connecting beams. Analysis using the theory reveals that the failure mode of a connecting beam depends mainly on the amount of longitudinal reinforcement provided. To ensure a ductile mode of failure, the steel ratio should be below $1.0 \%$, so that the rebars will yield well before the concrete fails. Overreinforcement should be avoided, as this will lead to brittle failure.

38. A non-linear finite element method for the analysis of slit shear walls which takes into account the non-linear shear-deflection behaviour of the connecting beams by using the softened truss model has been developed. The method can effectively deal with the non-linear load-deflection behaviour of slit shear walls throughout the entire loading history, including the post-peak range, and can thus be used to study the failure mode and to evaluate the ductility of slit shear wall structures.

39. A parametric study of the elasto-plastic behaviour of slit shear walls with different connecting beam designs has been carried out. It was found that the conversion of a solid shear wall into a slit shear wall by the introduction of vertical slits could substantially increase the ductility of the structure, but would, in general, reduce the lateral strength of the wall structure. With appropriate design, a slit shear wall system can have a more than $300 \%$ higher ductility than a solid shear wall of the same dimensions, at the expense of not more than $30 \%$ reduction in lateral strength.

40. The depth and reinforcement ratio of the connecting beams have a direct influence on the failure mode and ductility of a slit shear wall structure. For best overall performance, the connecting beams should be designed such that the beams have high ductility and yield not too long before the wall does. To ensure that the beams will yield before the wall does, but not prematurely, it is recommended that the beams should have a yield strength within $50-100 \%$ of the shear load that they will be subjected to if they remain elastic when the wall yields.

\section{Acknowledgement}

41. The financial support of the Croucher Foundation for the research work presented herein is gratefully acknowledged.

\section{References}

1. Japan Building Center. Technological development of earthquake-resistant structures. A. A. Balkema, Brookfield, Vermont, 1993.

2. Воотн E. Concrete structure in earthquake regions - design \& analysis. Wiley, New York, 1994.

3. Fintel M. Ductile shear walls in earthquake resistant multistory buildings. American Concrete Institute Journal, 1974, 71, No. 6, 296-305.

4. Kwan A. K. H., Lu X. L. and Cheung Y. K. Elastic analysis of slitted shear walls. International Journal of Structures, 1993, 13, No. 2, 75-92.

5. Cheung Y. K., Kwan A. K. H. and Lu X. L. Shear tests on simulated connecting beams in reinforced concrete slit shear walls. Proceedings of the Institution of Civil Engineers, Structures \& Buildings, 1993, 99, 481-488.

6. Kwan A. K. H., Lu X. L. and Cheung Y. K. Cyclic behaviour of connecting beams in reinforced concrete slit shear wall. Proceedings of the Institution of Civil Engineers, Structures \& Buildings, 1994, 104, 317-324.

7. Kwan A. K. H., Lu X. L. and Cheung Y. K. Large scale model tests of r.c. slit shear walls. International Journal of Structures, 1994, 14, No. 2, 63-82.

8. Vecchio F. and ColLins J. Stress-strain characteristics of reinforced concrete in pure shear. Final Report, IABSE Colloquium on Advanced Mechanics of Reinforced Concrete (Delft). International Association for Bridges \& Structural Engineering, Zurich, 1981.

9. Hsu T. T. C. Softened truss model theory for shear and torsion. American Concrete Institute Journal, 1988, 85, No. 6, 624-635.

10. Zienkiewicz O. C. and Taylor R. L. The finite element method, McGraw-Hill, London, 1991, 4th edn, vol. 2.

Please email, fax or post your discussion contributions to the Publisher: email: ttjournals@ice.org.uk; Fax: 0171538 9620; or post to Terri Harding, Journals Department, Thomas Telford Limited, Thomas Telford House, 1 Heron Quay, London E14 4JD 